\title{
Comparison of the anatomical characteristics and physical and mechanical properties of oil palm and bamboo trunks
}

\author{
Suthon Srivaro ${ }^{1}$ Jantira Rattanarat ${ }^{2} \cdot$ Peerada Noothong ${ }^{2}$ \\ Received: 19 June 2017 / Accepted: 11 December 2017 / Published online: 17 January 2018 \\ (C) The Japan Wood Research Society 2018
}

\begin{abstract}
The aim of this work was to investigate the structure-property relationships of two different monocotyledon trunks: bamboo (Bambusa blumeana Schultes) and oil palm (Elaeis guineensis Jacq). Anatomical characteristics (fraction of fibers) and physical (density, water uptake, and swelling in the radial direction) and mechanical (modulus of rupture and modulus of elasticity) properties of bamboo and oil palm trunks were examined. The results showed that the examined properties of both species were mainly governed by fibers. Those of bamboo were mostly greater. Functions relating most of the examined properties to the density of both species were finally achieved. Based on the results obtained, it is suggested that bamboo has a higher potential for structural application, while oil palm wood is more likely to be utilized for non-structural purposes.
\end{abstract}

Keywords Oil palm $\cdot$ Bamboo $\cdot$ Anatomical characteristics $\cdot$ Physical and mechanical properties $\cdot$ Monocotyledon

\section{Introduction}

In Thailand, agricultural waste from rubber tree has been used as the main raw material in wood industries since 1997. However, oil palm and bamboo trees are currently of interest to be utilized as alternative raw materials for wood production [1-3]. The oil palm tree is one of the most important economic crops in Thailand next to the rubber tree. In the year 2015, the plantation area of oil palm trees

Part of this work has been presented at IUFRO Division 52017 Conference and SWST 60th International Convention. 12th-16th June 2017, the Pinnacle Hotel (Downtown Vancouver), Vancouver, Canada (Oral).

Suthon Srivaro

ssuthon@wu.ac.th; suthon_srivaro@yahoo.com

Jantira Rattanarat

jantira.ra@wu.ac.th

Peerada Noothong

tempotaa45@gmail.com

1 Materials Science and Engineering Program, School of Engineering and Resources, Walailak University, Thasala district, Nakhon Si Thammarat 80160, Thailand

2 Marine and Coastal Resources Management Technology Program, School of Engineering and Resources, Walailak University, Thasala district, Nakhon Si Thammarat 80160, Thailand was approximately 8000 million $\mathrm{m}^{2}$ which is about one-third of the rubber tree plantation area [4]. Agricultural wastes from oil palm trees, which have not been effectively utilized, still need to have value added. Bamboo is focused on, because it is a fast-growing tree that can be harvested at an early age of approximately $3-5$ years [5]. In addition, it has a higher strength compared to softwoods and hardwoods [6]. The plantation area of bamboo in the country is currently approximately 66 million $\mathrm{m}^{2}$ [7]. With a large amount of plantation area combinations of oil palm and bamboo trees, the trees could be a potential raw material for wood production in Thailand.

The trunk is the main part that would be utilized for wood production. Thus, understanding its structure-property relationship is essential. Physically, the trunks of oil palm and bamboo are rather different. The oil palm trunk is straight and tapers from the bottom to the top [8], while the bamboo culm is tubular in shape and separated by nodes [9]. However, from a microscopic point of view, their anatomical characteristics are similar consisting of vascular bundles surrounded by parenchyma cells [5, 8-10]. Arrangements of vascular bundles and parenchyma cells within trunk tissue are similar to that of fiber-reinforced composite materials, in which parenchyma cells act like a matrix and vascular bundles act like reinforcements [11]. Distribution of vascular bundles within the trunk of both species is not uniform but show similar trends. They congest in the periphery zone and 
gradually decrease to the inner region of cross section $[5,8$, $9,12]$. However, the properties of fiber and parenchyma cells are generally different for different wood species [10-13]. Thus, wood properties as a result of varying cell properties within the trunks of these two-wood species were of interest to be studied here.

Many attempts have been made to investigate the trunk properties of bamboo and oil palm. For example, Erwinsyah [8] reported that the density and mechanical properties of an oil palm trunk in the periphery zone were greater than those of the central zones. A similar trend of the results was also reported by Fathi [12] and Lim and Khoo [14]. The variation of properties along the radial direction of the trunk was also found in bamboos. Dixon et al. [15] reported that most of the mechanical properties of bamboos gradually decreased from the outer to the inner culm wall. In addition, it was also found that the top part of the bamboo culm showed greater mechanical properties $[1,16]$. However, among studies in the literature, no comparison of trunk structures and properties between bamboo and oil palm has been made. Since their anatomical structures are similar, the underlying relationship between the structure and properties of these two-wood species was of interest to be explored in this study. This information would be useful for the further utilization of bamboo and oil palm for wood production.

In this work, anatomical characteristics (fraction of fibers), and physical (density, water uptake, and swelling in radial direction) and mechanical (modulus of rupture and modulus of elasticity) properties of oil palm trunk (Elaeis guineensis Jacq) and bamboo culm (Bambusa blumeana Schultes) were examined. The obtained results were then compared.

\section{Materials and methods}

\section{Materials}

Two-meter-long oil palm (Elaeis guineensis Jacq) (trunk diameter $\sim 42 \mathrm{~cm}$ ) and bamboo (Bambusa blumeana Schultes) (outer diameter $\sim 6.5 \mathrm{~cm}$, and culm wall thickness $\sim 13 \mathrm{~mm}$ ) trunks from ground level, with one trunk for each species, were selected for this study. The ages of oil palm and bamboo trees were approximately 25 and 4 years, respectively. Oil palm and bamboo trunks were dried to a final moisture content of $12 \%$ using a laboratory kiln (drybulb temperature $=60^{\circ} \mathrm{C}$, wet-bulb temperature $=50^{\circ} \mathrm{C}$ ) and then converted into the specimens for the measurement of the volume fraction of fibers, density, water uptake, swelling in radial direction, modulus of rupture (MOR), and modulus of elasticity (MOE) with some modification to ASTM D143 [17]. To obtain specimens having different densities for the experiment, all test specimens were randomly collected along the cross section of the selected trunk for both oil palm and bamboo. The dimensions of the test specimens for the measurement of water uptake and swelling in the radial direction of oil palm and bamboo were approximately 4-5 mm (radial) $\times 10 \mathrm{~mm}$ (tangential) $\times 20 \mathrm{~mm}$ (longitudinal). The dimensions of specimens for flexural test (MOR and MOE) for oil palm and bamboo were approximately $5 \mathrm{~mm}($ radial $) \times 10 \mathrm{~mm}($ tangential $) \times 120 \mathrm{~mm}$ (longitudinal) and $3 \mathrm{~mm}($ radial $) \times 10 \mathrm{~mm}$ (tangential $) \times 80 \mathrm{~mm}$ (longitudinal), respectively. The fraction of fibers was determined using the same specimens used for the flexural test. Prior to the test, all specimens were kept in a conditioning room at a temperature of $20{ }^{\circ} \mathrm{C}$ and relative humidity of $65 \%$ for 1 month. The final moisture content of the specimens was approximately $12 \%$.

\section{Methods}

\section{Measurement of the volume fraction of fibers and density}

The volume fraction of fibers was determined using an image processing technique. The images of entire cross section of the oil palm and bamboo specimens used for the flexural test were taken using an optical microscope (ME600, Nikon, Japan) with a magnification of $50 \times$. Thus, for each specimen, there would be more than one digital micrograph depending on the actual size of the cross section of each specimen. To distinguish fibers from the matrix (parenchyma and vessel cells), the optical image was painted with black for fibers. The painted image was then imported into image processing software, namely, MultiSpec Application version 3.4 software (free ware) which was developed by Purdue University, USA to quantify the fraction of fibers (a ratio of the number of the black pixels to the total number of pixels) (see Fig. 1). The average fraction of fibers from all digital images of each cross section for each specimen was then determined. The weight and volume of the corresponding specimen were also measured for the determination of density. The number of test specimens of bamboo and oil palm was 34 and 50, respectively.

\section{Measurement of water uptake and swelling in the radial direction}

The weight and thickness in the radial direction of specimens at a $12 \%$ moisture content were measured. Then, each specimen was soaked in $20^{\circ} \mathrm{C}$ distilled water for $24 \mathrm{~h}$. The weight and thickness in the radial direction of the specimens were again measured after water immersion. Water uptake and swelling were then determined using the equation provided in ASTM D143 [17]. The number of test specimens of bamboo and oil palm was 96 and 43, respectively. 
Fig. 1 a Optical image of a bamboo cross section; b processed image of a bamboo cross section from MultiSpec Software showing the bamboo fibers and matrix with black and white colors, respectively; c optical image of an oil palm wood cross section; and $\mathbf{d}$ processed image of an oil palm cross section from MultiSpec Software showing oil palm wood fibers and matrix with black and white colors, respectively

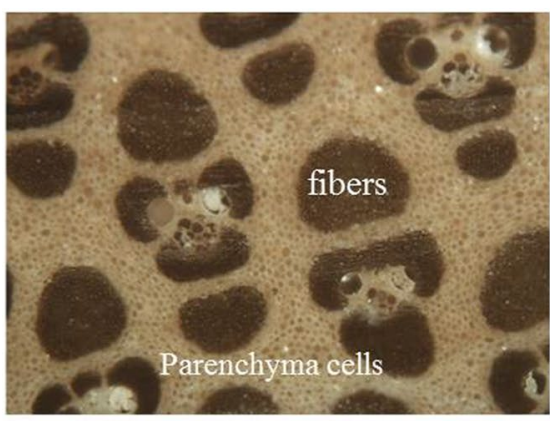

(a)

(b)

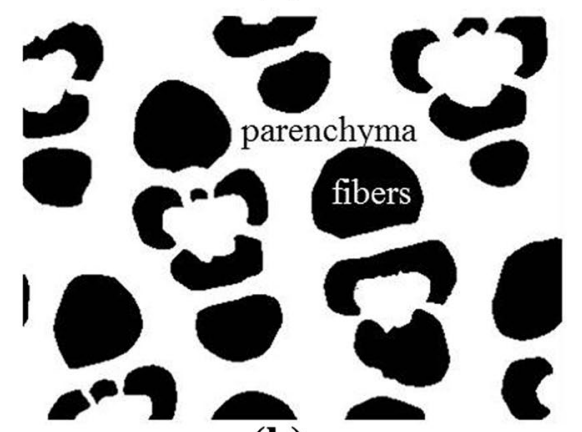

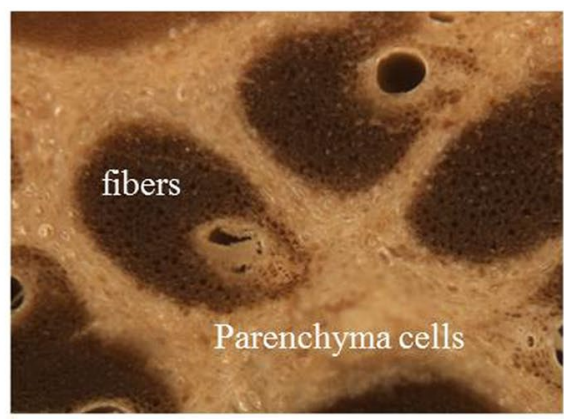

(c)

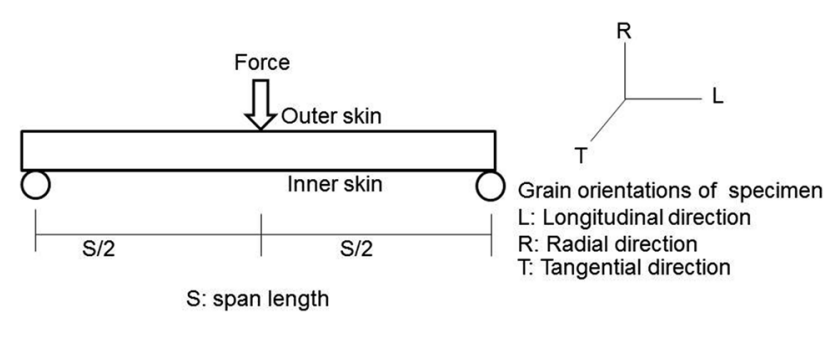

Fig. 2 Experimental set-up for the three-point bending test

\section{Measurement of MOR and MOE}

The three-point bending test was conducted to determine the MOR and MOE of oil palm and bamboo specimens. The experimental set-up is shown in Fig. 2. The span-tothickness ratio was kept constant at 20:1. Each specimen was loaded with a $150 \mathrm{kN}$ universal testing machine (Lloyd, UK) until fracture. The MOR and MOE were then determined using the equation provided in ASTM D143 [17]. The number of test specimens of bamboo and oil palm was 34 and 50 , respectively.

\section{Results and discussion}

\section{Anatomical characteristics}

The relationships between the fraction of fibers and density of bamboo and oil palm are shown in Fig. 3. It revealed

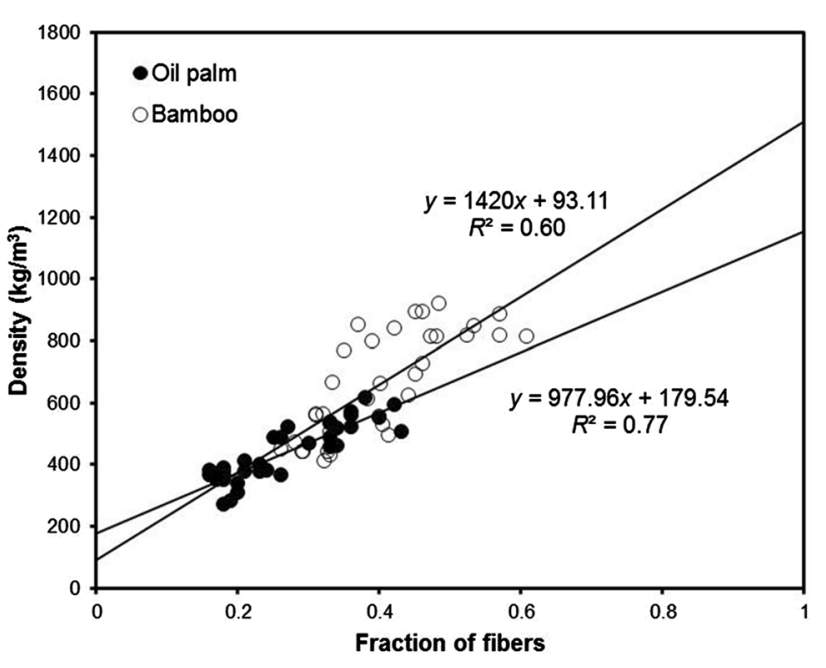

Fig. 3 Densities of oil palm and bamboo plotted against a fraction of fibers

that the densities of both species increased with the fraction of fibers as linear relationships, but their slopes were slightly different. In general, the density of fibers is much higher than that of parenchyma cells $[9,15,18]$. Therefore, densities of bamboo and oil palm should be mostly shared by fibers. Assuming that, densities of fiber and parenchyma cells within the trunks of both species were consistent. By means of the rule of mixtures, the densities of the fiber and matrix of bamboo and oil palm should be described by the following equation: 
$\rho_{\mathrm{w}}=\left(\rho_{\mathrm{f}}-\rho_{\mathrm{m}}\right) \mathrm{V}_{\mathrm{f}}+\rho_{\mathrm{m}}$,

where $\rho_{\mathrm{w}}$ is the density of wood, $V_{\mathrm{f}}$ is the fraction of fiber, $\rho_{\mathrm{f}}$ is the density of fiber, and $\rho_{\mathrm{m}}$ is the density of matrix.

Equation 1 indicates that the densities of the fiber and matrix could be determined by extrapolating the obtained linear equations in Fig. 3 to the vertical axis where the volume fraction of fiber is equal to one and zero, respectively. In doing so, the density of the matrix (obtained from the intersection point on the left vertical axis) could be determined by substituting the $V_{\mathrm{f}}$ value of zero into the obtained linear equations in Fig. 3. The calculated values were approximately 93 and $180 \mathrm{~kg} / \mathrm{m}^{3}$ for bamboo and oil palm, respectively. Likewise, the density of fiber (obtained from the intersection point on the right vertical axis) could be determined by substituting the $V_{\mathrm{f}}$ value of 1 into the obtained linear equations in Fig. 3. The calculated values were approximately 1513 and $1158 \mathrm{~kg} / \mathrm{m}^{3}$ for bamboo and oil palm, respectively. It was found that using the rule of mixtures from this study, the calculated fiber density of oil palm wood was highly corresponding to the measured ones (average density $\sim 1125 \mathrm{~kg} / \mathrm{m}^{3}$ ) reported in the literature [19]. It should also be noted that the obtained density of bamboo fiber was slightly higher than that of oil palm wood fiber (see Fig. 3).

\section{Physical properties}

Figure 4 shows the water uptake of bamboo and oil palm trunks plotted against the reciprocal of density. It showed that the water uptakes of oil palm trunks were mostly greater than those of bamboo. They ranged from 73 to 415 and 51 to $144 \%$ for oil palm and bamboo, respectively. In addition, it was found that water uptake decreased with increasing

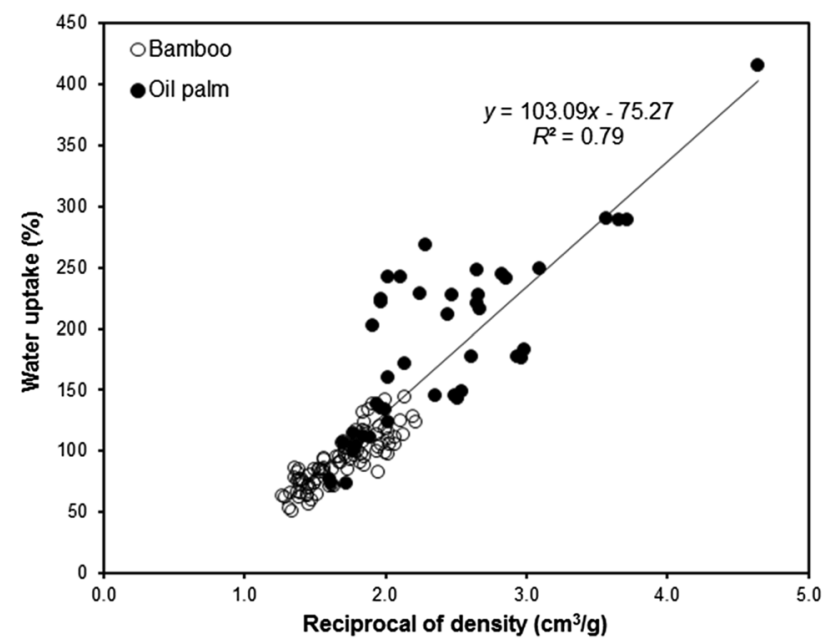

Fig. 4 Water uptake of oil palm and bamboo plotted against the reciprocal of density density for both species. In general, free water in the wood tissues of oil palm and bamboo is mostly contained in parenchyma cells, because these cells are thin-walled cells that provide many more cavities for containing water than thickwalled fiber cells [5, 12]. This leads to a lower water uptake at a higher density being obtained due to having a lower fraction of parenchyma cells for both species. It is interesting to note that the water uptake of oil palm and bamboo seems to fall into a single master curve as a linear relationship with the reciprocal of density regardless of wood species types, as shown in Fig. 4. Basically, a wood specimen consists of two components: solid wood content and void. At a given density, the fraction of voids of these two-wood species at a particular moisture content should be similar, because their cell wall densities are roughly the same at approximately $1500 \mathrm{~kg} / \mathrm{m}^{3}$ [20]. Thus, at a given apparent density, the water uptake of these two-wood species should also be identical due to having the same fraction of voids for containing water.

Swelling in the radial direction of oil palm and bamboo is shown in Fig. 5. They ranged from 3.6 to 25.9 and 1.3 to $36.4 \%$, respectively. Swelling in the radial direction of bamboo appeared to increase with density as a linear relationship, as shown in Fig. 5. It has also been reported that swelling of Dendrocalamus strictus bamboo was higher for higher density bamboo [21]. In general, this value in softwoods and hardwoods is greater for a higher density wood or thicker cell wall wood [22]. Thus, this value of the examined bamboo might be governed by fiber cells due to them having a thicker cell wall than parenchyma cells. Therefore, swelling in the radial direction of bamboo should be higher at a higher density due to having a higher fraction of fibers [5]. However, it was found that the swelling of oil palm wood appeared to be scattered with density (Fig. 5). This might

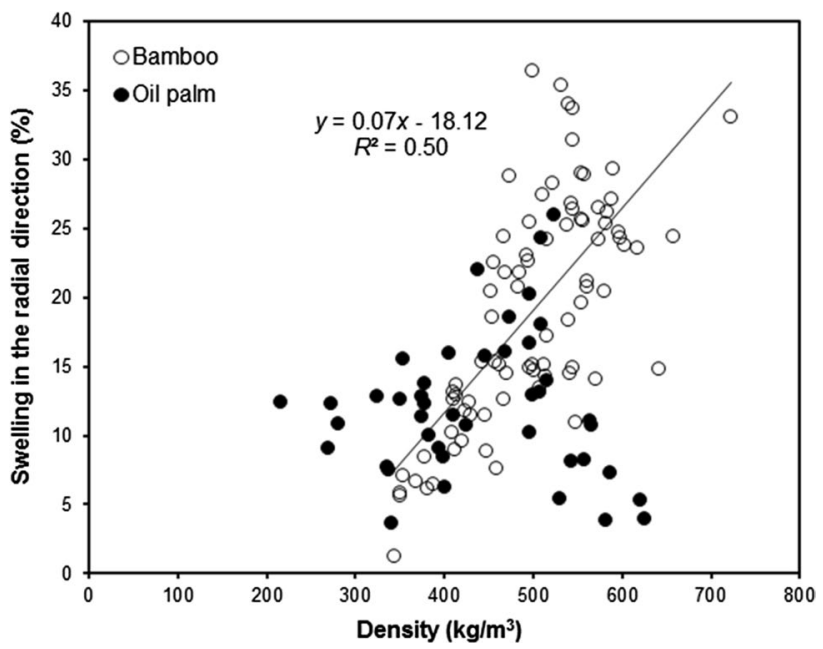

Fig. 5 Swelling in the radial direction of oil palm and bamboo at various densities 
be due to large variations in the anatomical characteristics of oil palm wood cells along the cross section [8], which could lead to variation in the swelling of each wood cell and caused the swelling of all the wood tissues to fluctuate. However, a greater understanding of the swelling mechanism of all the wood tissues as a result of the different swelling of fiber and parenchyma cells is still required. This is beyond the scope of this research work and should be investigated in the future. In addition, surface examination of the test specimens revealed that some of the test specimens of oil palm wood contained cracks, which might be affected by cutting during the preparation of the test specimens (see Fig. 6). The presence of cracks might also have caused the swelling in the radial direction of oil palm wood to fluctuate with density.

\section{Mechanical properties}

The MOR and MOE of bamboo and oil palm wood in relation to the fraction of fibers are shown in Fig. 7. They ranged from 53 to 275 and 7 to $58 \mathrm{MPa}$ for MOR, and 5-22 and 0.5-7.0 GPa for MOE, for bamboo and oil palm, respectively. All test specimens failed by bottom face fracture due to the tensile stress in the bottom face exceeding the tensile strength in the fiber direction of both species. It was observed that an increasing of fraction of fibers significantly increased both values of both species. This result indicates that fibers play an important role in both values of both species.

Moreover, it was found that at a given fraction of fibers, the MOR and MOE of bamboo were greater. This outcome implies that the stiffness and strength of bamboo fibers should also be greater and cause a higher MOR and MOE of bamboo to be obtained. In addition, it was also noticed that some vascular bundles in oil palm wood tissues deviated from the longitudinal direction, whereas they were strongly oriented in the axial direction in bamboo tissues (Fig. 8). This orientation might also contribute to the lower MOR and MOE of oil palm wood.



Fig. 6 Cracks observed in oil palm wood tissues
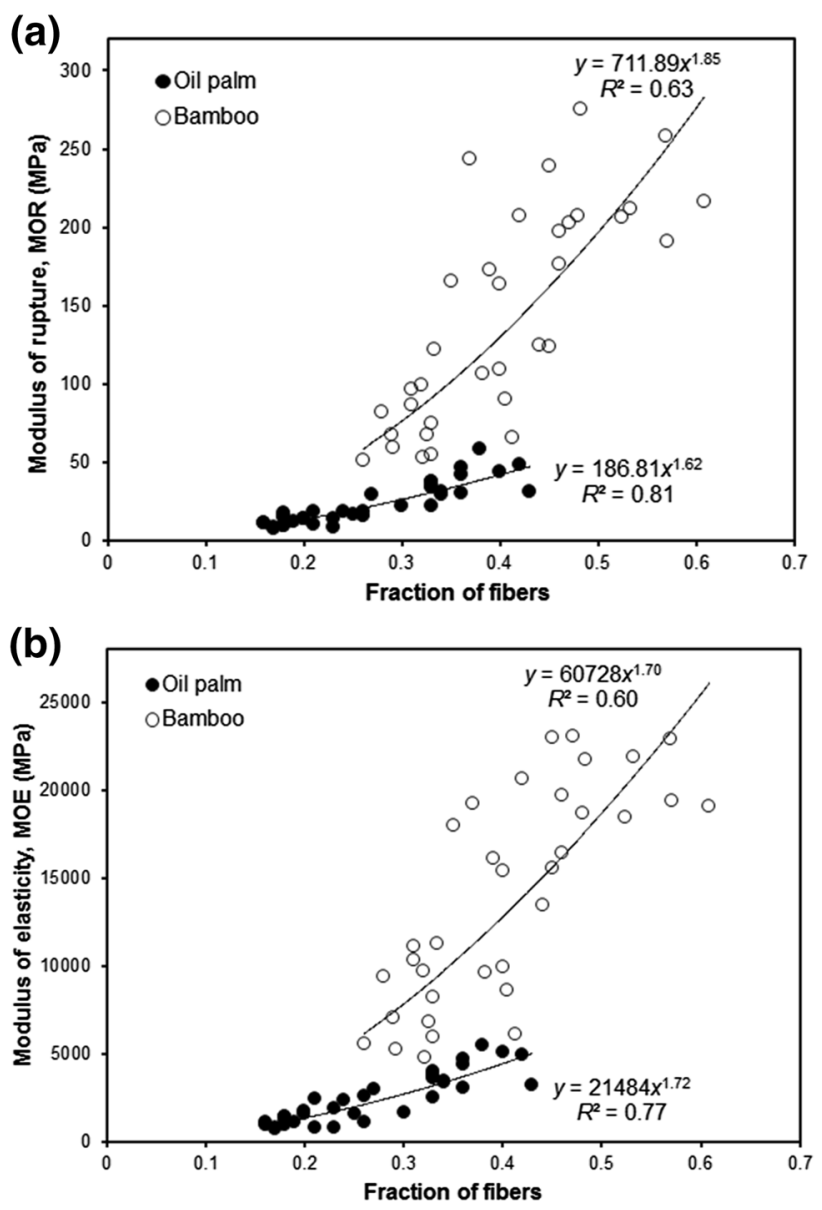

Fig. 7 a Modulus of rupture and $\mathbf{b}$ modulus of elasticity of bamboo and oil palm wood plotted against the fraction of fibers
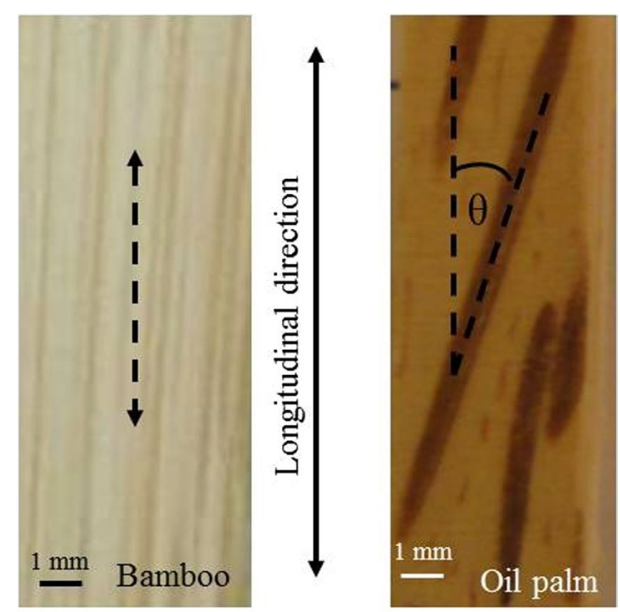

Fiber orientation

Fig. 8 Fiber orientations in bamboo and oil palm wood tissues 


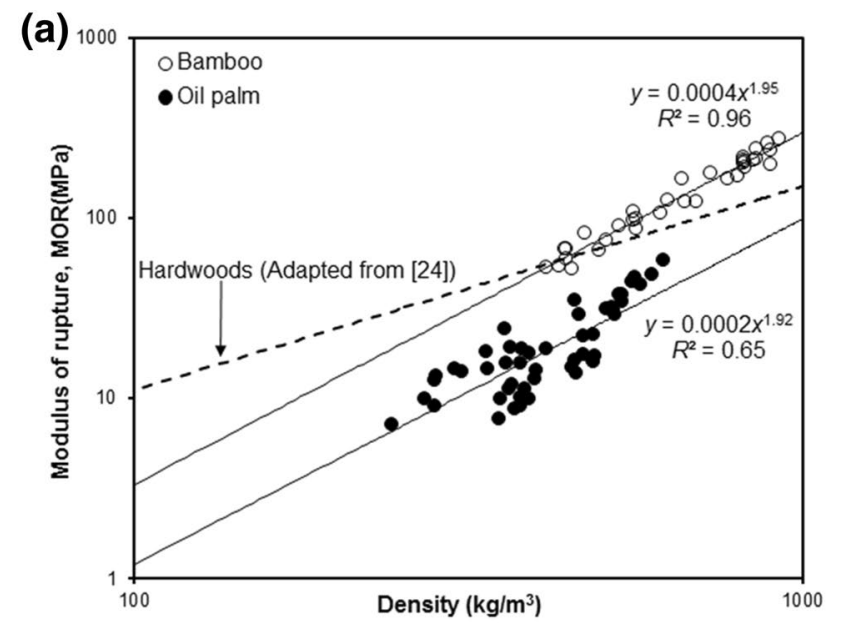

(b)

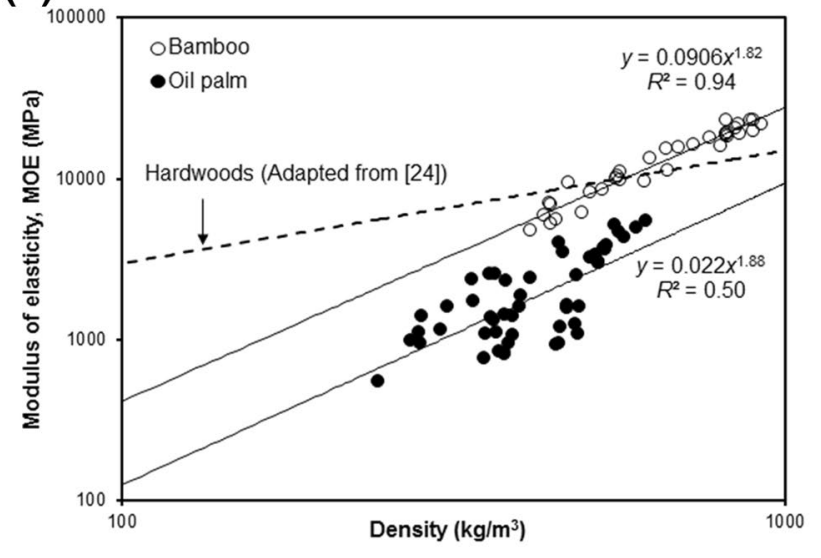

Fig. 9 Modulus of rupture and modulus of elasticity of oil palm and bamboo plotted against densities

Figure 9 shows the plots of the MOR and MOE of bamboo and oil palm wood in relation to density. Those of hardwoods reported in the literature [23] were also plotted into the same graph for comparison. It was found that the MOR and MOE of bamboo were the highest, followed by those of hardwoods and oil palm wood, respectively. In addition, it was also found that both values for bamboo and oil palm wood increased with increasing density as power law relationships with similar exponents for corresponding properties (Fig. 9). As mentioned above, the MOR and MOE of oil palm and bamboo were mainly contributed to by fibers, and both values increased with the fraction of fiber as a power law relationship. Therefore, an increasing MOR and MOE of these two-wood species as a result of increased density should also be a power law relationship, because density is strongly dependent on the fraction of fiber, as shown in Fig. 3.

It should also be noticed that the exponents for the MOR and MOE of bamboo and oil palm wood were highly corresponding to those of other palm species which was reported

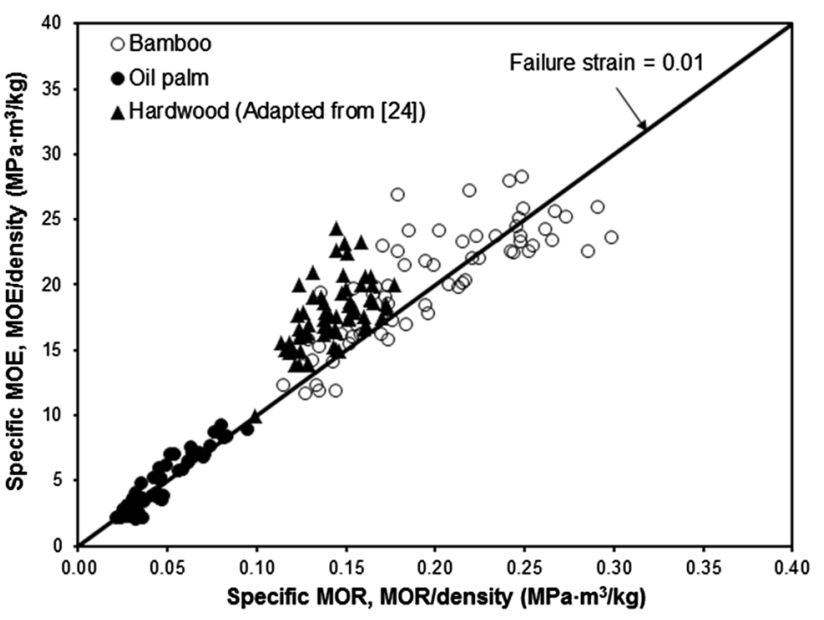

Fig. 10 Specific modulus of elasticity plotted against the specific modulus of rupture for oil palm, bamboo, and hardwood

to be approximately 2.05 for MOR and 2.46 for MOE, respectively $[18,24]$. However, these values were different from those of various softwood and hardwood species. The exponents for hardwoods and softwoods were reported to be approximately 1.13 and 0.7 , and 1.01 and 0.84 for MOR and MOE, respectively [23]. These different exponents might be due to different anatomical structures between the two-wood species (softwood/hardwood and bamboo/oil palm). Softwood and hardwood consist of a honeycomb-like structure of tracheid or fiber cells. While oil palm and bamboo tissues are made up of two different types of cells that are the honeycomblike structures of fiber cells surrounded by a closed cell foamlike structure of parenchyma cells [25]. It is clearly seen that oil palm and bamboo have a more heterogeneous structure in comparison to softwoods and hardwoods. This structure might have caused the different obtained exponents for MOR and MOE between the two-wood species.

In terms of structural performance, the specific MOR and MOE should be considered. Figure 10 shows both values for bamboo and oil palm wood. Those of hardwoods reported in the literature [23] were also plotted into the same graph for comparison. The result showed that bamboo showed the highest specific MOR and MOE followed by those of hardwoods and oil palm wood, respectively. However, it was noticed that the failure strain (strength to the Young's modulus ratio [26]) of bamboo and oil palm wood seemed to be roughly similar and slightly higher than those of hardwoods.

\section{Conclusions}

1. The density, water uptake, swelling in radial direction, and MOR and MOE of bamboo and oil palm wood were mainly contributed to by fibers. Most of the val- 
ues increased with the increasing fraction of fibers, except for those of water uptake for both species which decreased with fraction of fibers.

2. Swelling in the radial direction of bamboo linearly increased with density, whereas that of oil palm wood appeared to fluctuate with density.

3. Water uptake linearly increased with the reciprocal of density for both species.

4. MOR and MOE were related to density as power law relationships for both species.

5. At a given density, the MOR and MOE of bamboo were greater, whereas water uptakes between the two-wood species were similar.

6. Based on the obtained flexural properties, bamboo has a higher performance for structural applications, while oil palm wood is more likely to be utilized for non- structural purposes.

Acknowledgements This work was supported by Institute of Research and Development, Walailak University, Thailand (Grant no. WU59301).

\section{Compliance with ethical standards}

Conflict of interest The authors declare that they have no conflict of interest.

\section{References}

1. Malanit $P$ (2009) The suitability of dendrocalamus asper backer for oriented strand lumber. Ph.D. thesis, University of Hamburg, Germany

2. Srivaro S, Matan N, Chaowana P, Kyokong B (2014) Investigation of physical and mechanical properties of oil palm wood core sandwich panels overlaid with a rubberwood veneer face. Eur J Wood Prod 72(5):571-581

3. Srivaro S (2016) Utilization of bamboo as lightweight sandwich panels. Mater Sci Medzg 22(1):60-64

4. Jiasakul S (2015) Agricultural statistics of Thailand (in Thai). Official of Agricultural Economics, Thailand, pp 1-240

5. Grosser D, Liese W (1971) On the anatomy of asian bamboos, with special reference to their vascular bundles. Wood Sci Technol 5:290-312

6. Liese W (1998) The anatomy of bamboo culms (Inbar technical reports). International Network for Bamboo and Rattan, Beijing, pp 1-208

7. Tanurak S (1996) Economic bamboos (in Thai). Department of Agricultural Extension, Thailand, pp 1-78
8. Erwinsyah V (2008) Improvement of oil palm wood properties using bioresin. Ph.D. thesis, Technische Universitat Dresden, Germany

9. Sutnaun S, Srisuwan S, Jindasai P, Cherdchim B, Matan N, Kyokong B (2005) Macroscopic and microscopic gradient structures of bamboo culms. Walailak J Sci Tech 2(1):81-97

10. Amada S, Ichikawa Y, Munekata T, Nagase Y, Shimizu H (1997) Fiber texture and mechanical graded structure of bamboo. Compos Part B Eng 28B:13-20

11. Shao ZP, Fang CH, Huang SX, Tian GL (2010) Tensile properties of moso bamboo (Phyllostachys pubescens) and its components with respect to its fiber-reinforced composite structure. Wood Sci Technol 44:655-666

12. Fathi L (2014) Structural and mechanical properties of the wood from coconut palms, oil palms and date palms. PhD thesis, University of Hamburg, Germany

13. Shah DU (2013) Developing plant fiber composites for structural applications by optimizing composite parameter: a critical review. Mater Sci 48:6083-6107

14. Lim SC, Khoo KC (1986) Characteristics of oil palm trunk and its potential utilization. Malays For 49(1):3-21

15. Dixon PG, Ahvenainen P, Aijazi AN, Chen SH, Lin S, Augusciak PK, Borrega M, Svedström K, Gibson LJ (2015) Comparison of the structure and flexural properties of moso, guadua and tre gai bamboo. Constr Build Mater 90:11-17

16. Srivaro S, Jakranod W (2016) Comparison of physical and mechanical properties of Dendrocalamus asper Backer specimens with and without nodes. Eur J Wood Prod 74:893-899

17. ASTM D143 (2009) Standard test methods for small clear specimens of timber. ASTM International, USA

18. Rich PM (1987) Developmental anatomy of the stem of Welfia geogii, Iriartea gigantea and other arborescent palms: implications for mechanical support. Am J Bot 74:792-802

19. Faruk O, Bledzki AK, Fink HP, Sain M (2012) Biocomposites reinforced with natural fibers:2000-2010. Prog Polym Sci 37:1552-1596

20. Gibson LJ, Ashby MF (1998) Cellular solids: structure and properties. Pergamon, Oxford

21. Ahmad M, Kamke FA (2005) Analysis of Calcutta bamboo for structural composite materials: physical and mechanical properties. Wood Sci Technol 39:448-459

22. Glass SV, Zelinka SL (2010) Moisture relations and physical properties of wood. In: Ross RJ (ed) Wood handbook-wood as an engineering material. Forest product laboratory, Madison, pp 80-98

23. Kretschmann DE (2010) Mechanical properties of wood. In: Wood handbook: wood as an engineering material. Forest product laboratory, Madison, pp 100-145

24. Rich PM (1987) Mechanical structure of the stem of arborescent palms. Bot Gaz 148:42-50

25. Gibson LJ (2012) The hierarchical structure and mechanics of plant materials. J R Soc Interface 2012 9:2749-2766

26. Ashby MF (2005) Materials selection in mechanical design, 3rd edn. Butterworth-Heinemann, Oxford 